\title{
Synthesis of Porous CoO Nanorods @ N-doped Carbon as High- Performance Lithium Ion Battery Anode
}

\author{
Chenhao Zhao ${ }^{1,2}$, Ye Shen ${ }^{1}$, Zhibiao $\mathrm{Hu}^{1,2, *}$ and Xinxin Wang $^{3}$ \\ ${ }^{1}$ College of Chemistry \& Materials Science, LongYan University, Fujian LongYan, 364012, China. \\ ${ }^{2}$ Fujian Provincial Key Laboratory of Clean Energy Materials, LongYan University, Fujian LongYan, \\ 364012, China. \\ ${ }^{3}$ School of Chemical and Biological Engineering, QiLu Institute of Technology, Shandong Jinan, \\ 250200, China. \\ *E-mail: zhibiaohu@163.com
}

doi: $10.20964 / 2018.06 .65$

Received: 3 February 2018 / Accepted: 9 April 2018 / Published: 10 May 2018

Construction of porous-structure and carbon coated transition metal oxides is essential for their use as lithium ion battery anodes. In this study, $\mathrm{CoO}$ nanorods @ N-doped carbon have been prepared via a synchronous carbonization/reduction of $\mathrm{Co}_{3} \mathrm{O}_{4}$ nanorods @ polypyrrole composite. XRD patterns suggest the pure-phase $\mathrm{CoO}$ can be obtained when the added amount of pyrrole reaches an amount of $180 \mu \mathrm{L}$. SEM and TEM images show CoO with surface carbon layer can well inherit the porous nanorod structure of $\mathrm{Co}_{3} \mathrm{O}_{4}$ template, and partial nitrogen is doped into carbon backbone. As lithium ion battery anode, the optimal sample obtained at a pyrrole content of $270 \mu \mathrm{L}$ can deliver an initial discharge capacity of $923.9 \mathrm{mAh} \mathrm{g}^{-1}$ with high Coulombic efficiency of $75.6 \%$ at $200 \mathrm{mAg}^{-1}$, and a capacity value of $841.6 \mathrm{mAh} \mathrm{g}^{-1}$ can be kept after 100 cycles. Even at a high rate of $1000 \mathrm{mAg}^{-1}$, a stable discharge capacity of $570 \mathrm{mAh} \mathrm{g}^{-1}$ can also be reached. These promising electrochemical performances may be attributed to the synergistic effect of porous structure and carbon coating.

Keywords: Synchronous carbonization/reduction; pyrrole content; $\mathrm{CoO} @$ N-doped carbon; lithium ion battery anodes.

\section{FULL TEXT}

(C) 2018 The Authors. Published by ESG (www.electrochemsci.org). This article is an open access article distributed under the terms and conditions of the Creative Commons Attribution license (http://creativecommons.org/licenses/by/4.0/). 